\title{
Successful Surgical Management of Intestinal Foreign Body in a Labrador Dog
}

\author{
J. J. Parmar*, Neha Rao, P. B. Dabhi, A. I. Shah and D. M. Patel
}

Veterinary Clinical Complex, College of Veterinary Science and Animal Husbandry, Anand Agricultural University, Anand-388001, India

*Corresponding author

A B S T R A C T

\section{Keywords \\ Surgical management, Intestinal foreign Body, Labrador \\ Article Info \\ Accepted: \\ 18 May 2020 \\ Available Online: \\ 10 June 2020}

Three year old Labrador male weighing $27 \mathrm{~kg}$ dog was presented with history of complaint of off feed and straining for defection since two days. The abdominal diagnostic imaging suggested foreign body in intestine. The dog was operated for enterotomy and chewed plastic toy was recovered. The dog was recovered very well without any complications.

\section{Introduction}

Dogs may ingest foreign bodies (FBs) may lodge in any part of the intestinal tract that cause intestinal obstruction required emergency surgical treatment and most commonly are balls, stones, rubber, bones, and plastic are usually reported (Papazoglou et al., 2003). Gastrointestinal foreign bodies are commonly encountered in small animal practice. Due to indiscriminate eating habits, foreign bodies are more common in dogs and ingested foreign bodies pass uneventfully through the gastrointestinal tract results in to variable symptoms (Makinde et al., 2018).
This paper presents a successful surgical management of intestinal foreign body in Labrador dog.

\section{History and clinical examinations}

Three year old Labrador male weighing $27 \mathrm{~kg}$ dog was presented to Veterinary Clinical Complex, Veterinary College, Anand with complaint of off feed and straining for defection since two days. On presentation animal was active and alert. All physiological parameters were within normal range. Clinical palpation revealed hard mass in abdomen. Further abdominal radiography 
(Fig. 1) and ultrasonography (Fig. 2) was done to confirm etiology which revealed foreign body in intestine.

\section{Treatment and Discussion}

On the basis of clinical examinations and diagnostic findings the case was diagnosed as a foreign body in intestine. The surgical removal by enterotomy was planned. Preoperative animal was medicated with Inj. Atropine Sulphate $0.04 \mathrm{mg} / \mathrm{kg}$ subcutaneous, Inj. RL 500ml, Inj. Intacef Tazo@ 15mg/kg body weight intravenously. Under general anaesthesia usif Inj. Ketamine hydrochloride@ $5 \mathrm{mg} / \mathrm{kg}$ and Inj. Mediazolam@1 mg/kg intravenously and
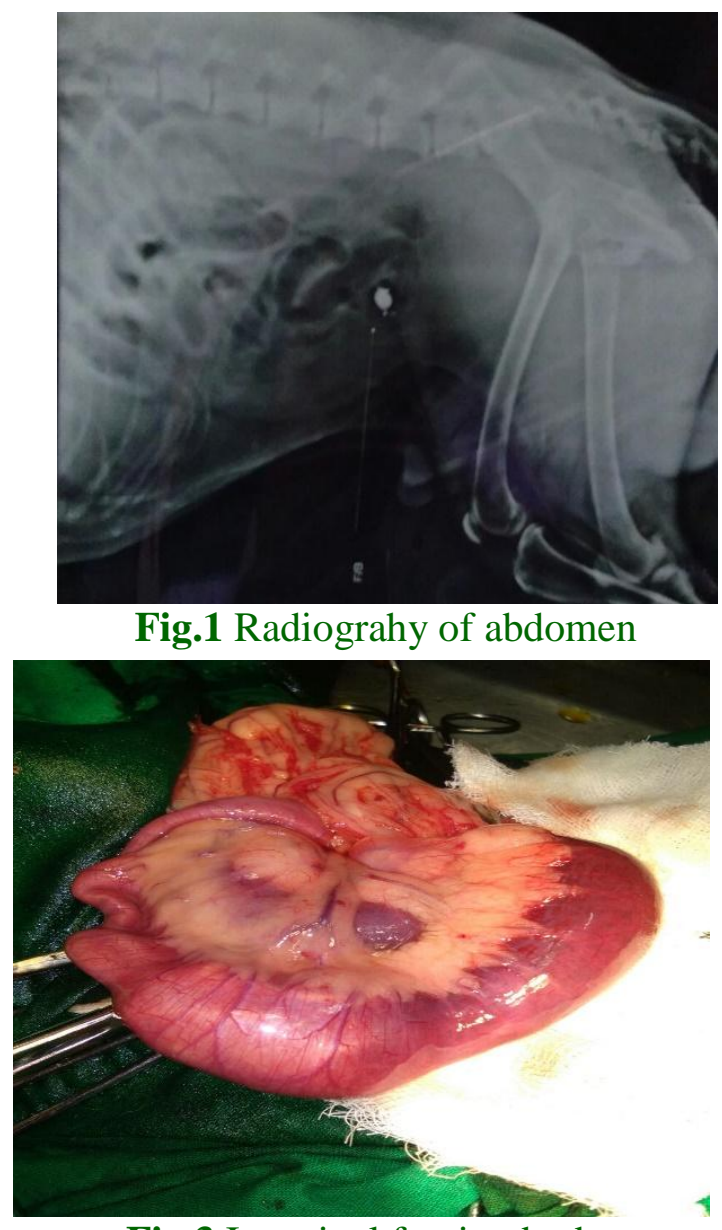

Fig.3 Intestinal foreign body enterotomy was performed and chewed plastic toy (Fig. 3, 4 and 5) was recovered. Enterotomy incision on antimesentric border was sutured by double layer suture pattern and abdominal muscles sutured by continuous lock stich and skin closure by interrupted suture pattern. Post-operatively dog was kept on total off water and off feed for five days and given Inj. RL 500ml, Inj. IntacefTazo@ $15 \mathrm{mg} / \mathrm{kg}$ intravenously. After five days dog was allowed liquid diet and after seven days solid food. Dog was recovered uneventfully without any complication within twelve days (Fig. 6). The dogs have habit of licking and playing with intimate objects which sometime engulfed and migrate to the intestine due to small size and lead to intestinal obstruction.

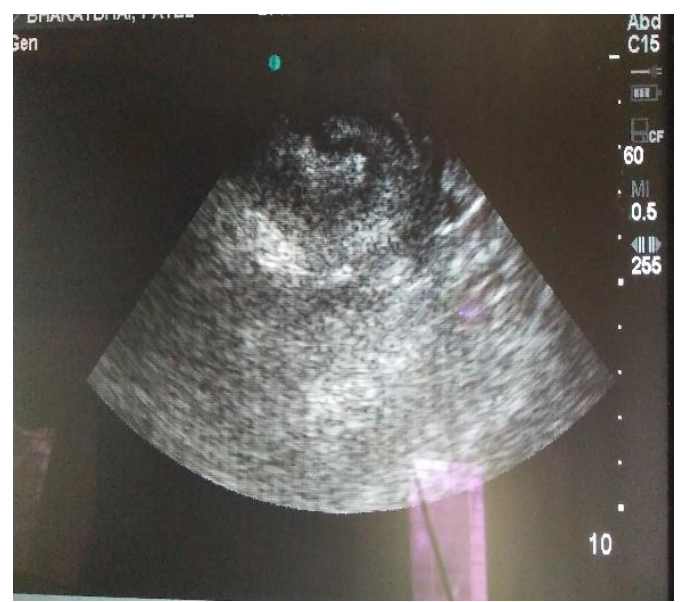

Fig. 2 Ultrasonography of foreign body

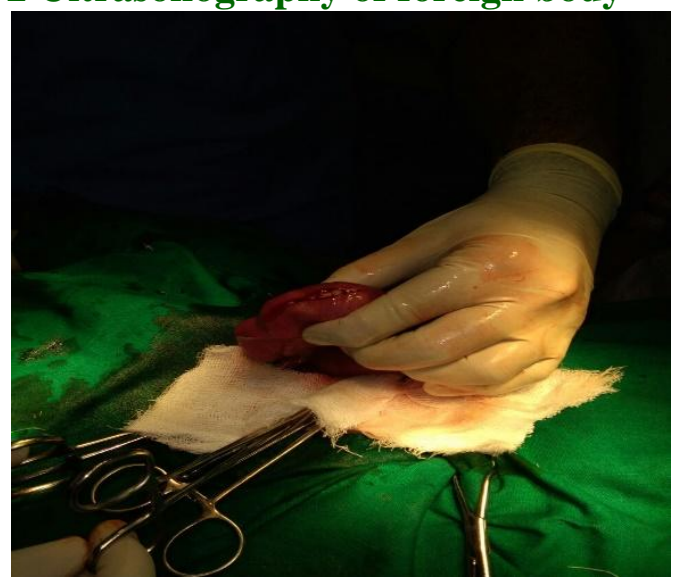

Fig. 4 Enterotomy Incision 


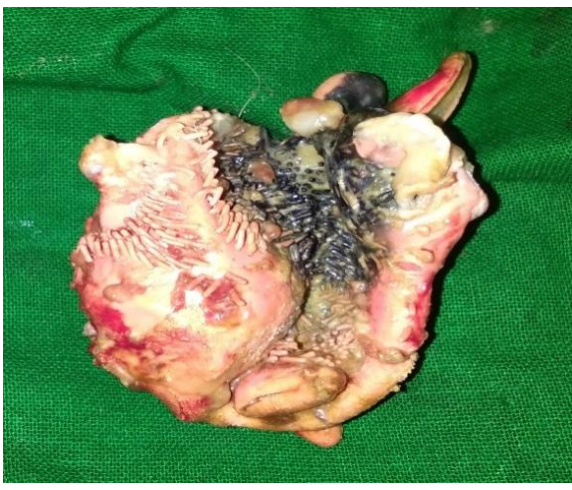

Fig.5 Plastic Toy

The abdominal palpation give some clue for the diagnosis. Radiography is commonly used in suspected gastrointestinal foreign bodies but plain abdominal radiographs may be unremarkable in many cases and abdominal ultrasonography may be required to confirm the diagnosis (Hoday et al., 2014). Kamalakar et al., (2018) performed enterotomy in Labrador bitch and recovered few pebbles. Mahesh et al., (2019) performed enterotomy and recovered spherical ball from six month old male Dobbermann. Timely diagnosis based on history, clinical symptoms and diagnostic findings confirms intestinal obstruction which need immediate surgical management to achieve favourable outcomes.

\section{Acknowledgements}

Authors are grateful to the Dean of the College and University authorities of AAU, Anand for the facilities provided for this work.

\section{References}

Hobday, M. M., Pachtinger, G. E., Drobatz, K. J. and Syring, R. S. (2014). Linear

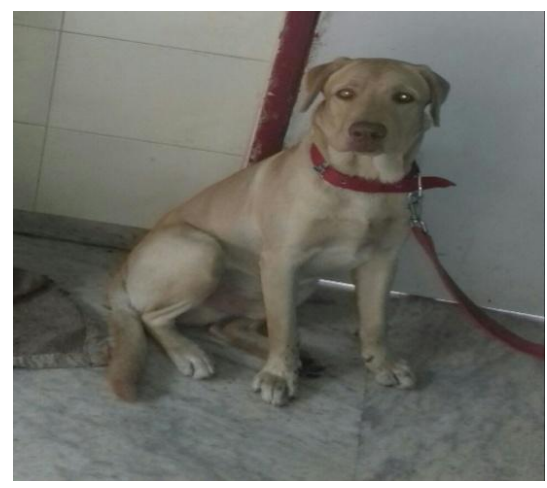

Fig.6 Recovered Dog

versus non-linear gastrointestinal foreign bodies in 499 dogs: clinical presentation, management and shortterm outcome. Journal of Small Animal Practice, 55: 560-565. DOI: 10.1111/jsap.12271

Kamalakar, G., Thara Singh, D., Lamani, L., Suresh, K., Saigunaranjan and Nagaraja, B.N. (2018). Surgical Management of Intestinal Obstruction due to Pebbles in a Labrador Dog. Journal of Livestock Science, 10:19-21. doi. 10.33259/JLivestSci.2019.19-21.

Mahesh, V., Jyothi Shree, S., Lathamani, V. S. and Nagaraja, B. N. (2019). Surgical retrieval of foreign body in dog - A case report. International Journal of Science, 8(5): 1044 - 1048.

Makinde, O. A., Adebayo, O. O., Adeniyi, A. A. and Ajadi, R. A. (2018). Jejunal linear foreign body obstruction in a three year old female Boerboel. Sokoto Journal of Veterinary Sciences, 16(4): 87 - 91.

Papazoglou, L. G., Patsikas, M. N. and Rallis, T. (2003). Intestinal Foreign Bodies in Dogs and Cats. Compendium, 25(11): 830-844.

\section{How to cite this article:}

Parmar, J. J., Neha Rao, P. B. Dabhi, A. I. Shah and Patel, D. M. 2020. Successful Surgical Management of Intestinal Foreign Body in a Labrador Dog. Int.J.Curr.Microbiol.App.Sci. 9(06): 1643-1645. doi: https://doi.org/10.20546/ijcmas.2020.906.202 